Transactions of the American Fisheries Society 130:376-384, 2001

(C) Copyright by the American Fisheries Society 2001

\title{
Survival of Juvenile Lemon Sharks at Bimini, Bahamas, Estimated by Mark-Depletion Experiments
}

\author{
SAMUEL H. GRUBER \\ Bimini Biological Field Station, Rosenstiel School of Marine and Atmospheric Science, \\ University of Miami, 4600 Rickenbacker Causeway, Miami, Florida 33149, USA \\ Jean R. C. DE MarignaC \\ Moss Landing Marine Laboratories, California State University, \\ 8272 Moss Landing Road, Moss Landing, California 95309, USA \\ JOHN M. HoENIG* \\ Virginia Institute of Marine Science, College of William and Mary, \\ Post Office Box 1346, Gloucester Point, Virginia 23062-1346, USA
}

\begin{abstract}
The survival rate of juvenile lemon sharks Negaprion brevirostris in North Sound, Bimini, Bahamas, was estimated by marking a cohort of small sharks ( $\leq 53 \mathrm{~cm}$ precaudal length) each spring from 1995 to 1999 and by estimating the number of survivors 1 year later by using a depletion method on the marked population. Annual survival rate estimates varied between $38 \%$ and $65 \%$, which was somewhat higher than the $39 \%$ steady-state survival predicted from a life cycle (Leslie matrix) model. These are the first direct estimates of the survival rate of a juvenile elasmobranch, and the results support modeling efforts that have been used in determining limits to sustainable exploitation of elasmobranchs. Estimates of survival rates in the present study were negatively correlated with estimated initial abundance and are consistent with strong, densitydependent survival.
\end{abstract}

As a group, sharks are generally characterized as having slow growth, late maturity, low fecundity, low natural mortality, and long lifespan relative to teleost fishes. This suite of life history traits defines a life history strategy that has important implications for the ecology, evolution, and management of shark populations. However, estimates of life history parameters are incomplete for almost all shark species.

We have intensively investigated the biology and ecology of the lemon shark Negaprion brevirostris at Bimini, Bahamas, to obtain quantitative estimates of life history parameters (Gruber and Stout 1983; Brown and Gruber 1988; Hoenig and Gruber 1990; Morrissey and Gruber 1993a, 1993b). We believe the lemon shark has a life history typical of large coastal sharks, and this, coupled with the extensive available information, enables us to use the species as a heuristic model. Thus, Hoenig and Gruber (1990) used a Leslie matrix model to synthesize the available life history information and estimate the survival rate of age-0 lemon sharks. They then explored the sustainability of a theoretical fishery for the lemon

* Corresponding author: hoenig@ vims.edu

Received March 17, 2000; accepted October 24, 2000 shark by examining how much life history traits would have to change to accommodate a given level of fishing mortality. Subsequently, Hoff (1990), Cortes (1998), and Sminkey and Musick (1996), among others, performed similar analyses for other species and concluded, as we did, that shark populations cannot withstand heavy fishing mortality. However, in all these studies the investigators implicitly assumed that the natural mortality rate of young sharks could be inferred from a Leslie or life table model of a steady-state population.

As far as we know only one investigation (Manire and Gruber 1993) has attempted to directly measure the survival of juveniles of any species of elasmobranch. They obtained estimates of annual survival ranging from $36 \%$ to $55 \%$, depending on choice of estimator, in a 1-year pilot study of lemon sharks conducted at Bimini in an area where juveniles are unexploited. These values are close to the $39 \%$ value inferred by Hoenig and Gruber (1990) from a Leslie matrix model of the life cycle under equilibrium conditions.

Conditions at Bimini are well-suited for estimating the survival rate of juvenile lemon sharks. Bimini Lagoon contains pupping grounds and nursery areas for lemon sharks, and extensive data on the life history of the juveniles in the lagoon 
demonstrate that they have high site fidelity and limited home ranges (Morrissey and Gruber 1993a; b). In particular, the North Sound area of Bimini appears to contain an almost closed population of young sharks with respect to immigration and emigration.

We extended the study of Manire and Gruber (1993) and modified their experimental design to rectify a technical problem that they reportednamely, that juvenile lemon sharks apparently learn to avoid the nets when gillnetting episodes occur within 6 months of each other. In our study, sampling was thus restricted to a single period in each of 5 years. In addition, we calculated survival estimates four ways to determine the robustness and reproducibility of the results.

In this paper we show, for the first time, direct field measurements of the survival rate of an unexploited population of juvenile sharks. Our estimates of annual survival compare favorably with the theoretical prediction derived by Hoenig and Gruber (1990) from the Leslie matrix model.

\section{Methods}

Study site.-The study was conducted in the northern part of Bimini Lagoon, Bimini, Bahamas $\left(25^{\circ} 44 \mathrm{~N}, 79^{\circ} 16 \mathrm{~W}\right)$. Sharks were captured in two areas: North Sound and Sharkland (Figure 1). Both sites are shallow nurseries with a maximum depth of about $2 \mathrm{~m}$. However, at low-water much of the area is exposed and most places are less than a meter deep. North Sound is almost completely fringed by mangroves. A narrow passage connects North Sound to Sharkland, which is more open. Juveniles tend to stick close to the shoreline in both areas and generally avoid the deeper parts of the lagoon.

Field methods.-During May 25 to June 10 in 1995-1999, juvenile lemon sharks were gillnetted for up to 6 nights in North Sound. This procedure was then repeated in Sharkland. These dates were selected so that parturition would have been completed just before sampling. Three monofilament gillnets $(180 \mathrm{~m} \times 150 \mathrm{~cm})$ having $10-\mathrm{cm}$ stretch mesh were fished for $12 \mathrm{~h}$ starting around dusk. The nets were perpendicular to the shore, one end tied to the mangroves and the other end anchored.

Nets were checked every time a splash was heard but no less frequently than every $15 \mathrm{~min}$. Sharks were removed immediately and placed in a 100-L container with seawater for transport by boat to a central examination site (Figure 1). Here they were placed in a trough filled with seawater while they were measured, sexed, and examined

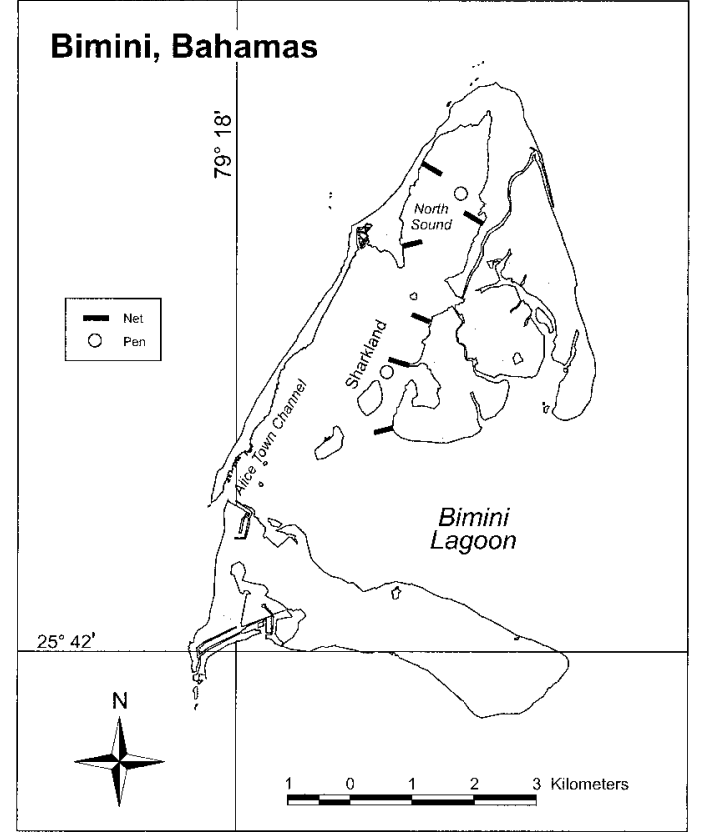

Figure 1.-Map of study area at Bimini, Bahamas, showing locations of gill-net sampling sites and the holding pens in North Sound and Sharkland. Nets and holding pens are not drawn to scale.

for the presence of a passive integrated transponder (PIT) tag. A 12-gauge hypodermic needle was used to inject a PIT tag through the musculature and skeletal elements below the first dorsal fin of any untagged shark. All sharks were then weighed and held in a pen $(10 \times 15 \mathrm{~m})$ at the examination site for the duration of the fishing activities (up to 6 nights in a 9-d period). Sharks were fed pieces of filleted fish every other day while in the pen.

Analytical methods.-Our estimates of survival rates for North Sound lemon sharks were restricted to those $40-53 \mathrm{~cm}$ precaudal length (PCL) at time of tagging (49-66 cm total length per Gruber and Stout 1983). This size range encompasses age-0 sharks but also includes a few age-1 and age-2 sharks (Brown and Gruber 1988; Gruber, unpublished observations on data from this study).

In the course of the fieldwork, a few sharks may die due to the stress of capture, handling, and captivity. The handling mortality, $H$, is

$$
H=\frac{\text { number dying due to handling }}{\text { number of fish caught }} \text {. }
$$

The finite rate of fishing mortality (or exploitation rate), $u$, is the fraction of the population killed during the gillnetting and tagging operations: 


$$
u=\frac{\text { number dying due to handling }}{\text { number in the population }} \text {. }
$$

We estimated the number of sharks in the population from the declining catches over the nights of sampling by using Leslie's depletion estimator (Leslie and Davis 1939) as modified by Braaten (1969). This consists of regressing the catch per night on the cumulative catch, which is defind as the sum of all animals caught on previous nights plus one half the catch on the current night. The intercept with the abscissa is an estimate of the initial population size, and the absolute value of the slope is an estimate of the catchability coefficient, $q$.

For any given year, $i$, the estimated annual survival rate, $S_{i}$, of sharks in North Sound was determined by estimating the number of individuals surviving 1 year after they were tagged. Because some sharks moved between North Sound and Sharkland, it was necessary to determine the number of tagged sharks in each area. Thus,

$s_{i}=$ (estimated survivors in North Sound and

$$
\begin{aligned}
& \text { West Sharkland in year } i+1) \\
& \div(\text { number tagged in North Sound in year } i) \text {. }
\end{aligned}
$$

The number of survivors in North Sound was estimated from the rate of decline in the catch of sharks marked the year before. That is, a depletion estimator was applied to the catches of marked sharks. Note that the number of recaptured sharks tagged the year before could be greater than the Leslie depletion estimate of the survivors; when this happened, we used the actual number of recaptures as the estimate of survivors because this was the minimum feasible estimate.

The number of emigrants from North Sound to Sharkland was estimated as the number of sharks tagged in North Sound that were recaptured in Sharkland during the following spring sampling. We refer to this as the "observed emigration." It is a minimal estimate because some emigrants may have escaped capture in Sharkland. To obtain an alternative estimate of the number of emigrants in Sharkland, we used the depletion method to estimate the number of marked and unmarked juvenile lemon sharks in Sharkland and multiplied this by the observed ratio of marked:unmarked animals in the catch in Sharkland. We refer to this as the "computed emigration." The estimates of population size in Sharkland were for sharks $62 \mathrm{~cm}$ or less PCL ( $\leq 78 \mathrm{~cm}$ total length) because we found this was the largest size any tagged shark up to 53 $\mathrm{cm}$ PCL attained after 1 year at liberty.

If in subsequent years, the recapture of additional sharks from a tagged cohort caused the known number of survivors to exceed the number of survivors estimated by the above procedure, we replaced the estimate by the known number of survivors. This assured that the estimate was feasible.

For the second year and all subsequent years of tagging, we chose two ways to define the marked cohort. One way was to consider the marked cohort being followed as just the sharks that were newly tagged; we call this the "newly tagged cohort." The other way was to define the marked cohort as all tagged sharks $53 \mathrm{~cm}$ or less PCL that were known to be alive (i.e., the newly tagged animals plus any animals tagged the previous year that were recaptured in the subsequent year and rereleased at a size $\leq 53 \mathrm{~cm}$ PCL). We call this the "augmented cohort."

Thus, we developed four related methods for estimating the annual survival rate. These methods differed according to how the marked cohort was defined and how emigration from North Sound was estimated.

Example.-During the 5 nights of gillnetting in North Sound in 1996, we successively removed $17,5,3,9$, and 2 juvenile lemon sharks $(\leq 53 \mathrm{~cm}$ PCL; Table 1). Of these 36 sharks, 1 died in the holding pen (and it did not have a tag at the time of capture). Thus, the handling mortality was $2.8 \%$ (1/36; Table 2). From the five nightly catches, we used the Leslie depletion method to estimate a population of 38.9 sharks, rounded to 39 (Table 2). Note that this was very close to the actual number of sharks captured, which was 36 . The finite rate of fishing mortality due to the field operations was estimated to be $2.6 \%(1 / 39$; Table 2$)$. Nine of the sharks had tags that were applied the previous year in North Sound. Thus, the newly tagged cohort contained 26 tagged sharks and the augmented cohort contained $26+9=35$ tagged sharks released into North Sound (Table 1).

Over 6 nights of gillnetting in North Sound in 1997 , the numbers of recaptures from the newly tagged cohort of 1996 were $8,3,3,0,0$, and 0 (14 sharks, Table 3). According to the Leslie depletion method, the population estimate for the tagged sharks was 14.4 animals. In this case, the Leslie method can be considered to estimate that all available sharks were caught because the population estimate was equal to the observed catch. Two sharks tagged in North Sound in 1996 were recovered in Sharkland in 1997 (observed emi- 
TABLE 1.-Capture and tagging data by night for lemon sharks $53 \mathrm{~cm}$ or less precaudal length (PCL) caught in North Sound, with or without tags. Blank cells indicate no sampling occurred.

\begin{tabular}{|c|c|c|c|c|c|c|c|c|c|c|}
\hline \multirow[b]{2}{*}{ Year } & \multicolumn{6}{|c|}{ Number caught on night } & \multirow[b]{2}{*}{ Killed $^{\mathrm{a}}$} & \multirow{2}{*}{$\begin{array}{c}\text { Pre- } \\
\text { viously } \\
\text { tagged }^{b}\end{array}$} & \multirow{2}{*}{$\begin{array}{l}\text { Newly } \\
\text { tagged }\end{array}$} & \multirow{2}{*}{$\begin{array}{l}\text { Aug- } \\
\text { mented } \\
\text { cohort }^{c}\end{array}$} \\
\hline & 1 & 2 & 3 & 4 & 5 & 6 & & & & \\
\hline 1995 & 42 & 13 & 4 & & & & 1 & 0 & 58 & 58 \\
\hline 1996 & 17 & 5 & 3 & 9 & 2 & & $1^{\mathrm{d}}$ & 9 & 26 & 35 \\
\hline 1997 & 36 & 4 & 7 & 9 & 4 & 3 & 0 & 13 & 50 & 63 \\
\hline 1998 & 27 & 7 & 2 & 2 & 0 & 6 & $2^{d}$ & 12 & 30 & 42 \\
\hline 1999 & 35 & 5 & 3 & 2 & & & 0 & 3 & 42 & 45 \\
\hline
\end{tabular}

a The number of sharks that died during the field operations.

b Sharks caught in a previous year that were still $53 \mathrm{~cm}$ or less (PCL) when recaptured.

${ }^{\mathrm{c}}$ The number of tagged sharks ( $\leq 53 \mathrm{~cm}$ PCL) known to be alive at the completion of the year's tagging operations or the sum of the previously tagged animals that are still $53 \mathrm{~cm}$ or less and the newly tagged animals.

${ }^{\mathrm{d}}$ Not bearing a tag.

gration; Table 4). In addition, one shark tagged in North Sound in 1996 was not seen in 1997 but was subsequently recaptured. Thus, we know that at least $14+2+1=17$ sharks must have survived, and the estimate of the annual survival rate in 1996, based on the observed emigration, is 17/ $26=0.65$.

The field operations in Sharkland in 1997 resulted in the following nightly catches of sharks $62 \mathrm{~cm}$ or less PCL: 44, 5, 4, 2, and 25 (Table 4). Clearly, the catch rate does not show the expected strong linear decline over time. The population estimate was 75.1 by the Leslie method, but because 80 animals were actually caught, we replaced the Leslie estimate by the number of sharks caught (Table 5). Of the 80 individuals captured in Sharkland, 2 (2.5\%) were emigrants from the North Sound newly tagged cohort of 1996 (Table 4). Hence, we estimated the total number of emigrants from North Sound to be $80 \times 0.025=2$, the same as the observed emigration. This produces an estimated number of survivors of $2+14$ $=16$. However, as noted above, 1 shark tagged in 1996 was not seen in 1997 but was subsequently

TABLE 2.-Estimated lemon shark population size in North Sound (total of tagged and untagged sharks $\leq 53 \mathrm{~cm}$ precaudal length), handling mortality $(H)$, and fraction killed $(u)$ during field operations.

\begin{tabular}{llcll}
\hline Year & $\begin{array}{c}H \\
(\%)\end{array}$ & $\begin{array}{c}\text { Estimated } \\
\text { population } \\
(\text { method) }\end{array}$ & $\begin{array}{l}R^{2} \text { for } \\
\text { Leslie } \\
\text { estimate }\end{array}$ & $\begin{array}{c}u \\
(\%)\end{array}$ \\
\hline 1995 & 1.7 & $61(\mathrm{~L})$ & 1.00 & 1.6 \\
1996 & 2.8 & $39(\mathrm{~L})$ & 0.58 & 2.6 \\
1997 & 0 & $63(\mathrm{C})$ & 0.72 & 0 \\
1998 & 4.5 & $44(\mathrm{C})$ & 0.86 & 4.5 \\
1999 & 0 & $45(\mathrm{C})$ & 0.98 & 0 \\
\hline
\end{tabular}

a Derived from the capture data in Table 1 as the maximum of the Leslie population estimate (L) and the number of sharks caught (C). recaptured. Thus, the number of survivors must have been at least 17 , and the estimated survival rate was $17 / 26=0.65$.

We performed a set of parallel computations with the augmented cohort replacing the newly tagged cohort. The augmented cohort created in 1996 contained 35 sharks (Table 1). Based on the 20 recaptures in 1997 (Table 6), we used the Leslie method to estimate that 21 of these animals were still alive in North Sound. Our estimate of emigration, based on the observed count, was 3 sharks, the same as the computed emigration (Table 4). Therefore, the estimates of survival in 1996, based on the two estimates of emigration, are the same: $(21+3) / 35=0.69$ (Table 7$)$.

\section{Results}

Handling mortality, $H$, ranged from $0 \%$ to $4.5 \%$ in the North Sound (Table 2). In Sharkland it ranged from $0 \%$ to $6.6 \%$, except in 1998 when it was $11.1 \%$ (Table 5). In both areas, the highest handling mortality occurred in 1998 and the lowest in 1997.

Estimates of population size of lemon sharks up to $53 \mathrm{~cm}$ PCL in North Sound ranged from 39 in 1996 to 63 in 1997 (Table 2). For 3 of the 5 years, we replaced the Leslie estimate with the total catch because the latter was higher than the Leslie estimate. For Sharkland, the estimated number of sharks up to $62 \mathrm{~cm}$ PCL ranged from 80 to 315 $($ median $=92$, mean $=135$; Table 5$)$. The estimate for 1996 was more than three times higher than the estimate for any other year. Two Leslie estimates were replaced with the total catch.

The Leslie estimates of total population in Sharkland and of the number of tagged survivors in North Sound were generally close to the total number of animals caught, indicating that the field sampling captured most of the population. This is 
TABLE 3.- Recaptures in North Sound of lemon sharks tagged in North Sound the previous year (when they were $\leq 53 \mathrm{~cm}$ precaudal length) and estimated number of survivors. Blank cells indicate that no sampling occurred; $\mathrm{L}=$ Leslie estimate; $\mathrm{C}=$ total number caught.

\begin{tabular}{|c|c|c|c|c|c|c|c|c|c|}
\hline \multirow{2}{*}{$\begin{array}{l}\text { Samp- } \\
\text { ling } \\
\text { year }\end{array}$} & \multirow{2}{*}{$\begin{array}{c}\text { Year } \\
\text { tagged }\end{array}$} & \multicolumn{6}{|c|}{$\begin{array}{c}\text { Number recaptured } \\
\text { on night }\end{array}$} & \multirow{2}{*}{$\begin{array}{l}\text { Estimated } \\
\text { survivors } \\
\text { (method) }\end{array}$} & \multirow{2}{*}{$\begin{array}{c}R^{2} \text { for } \\
\text { Leslie } \\
\text { esti- } \\
\text { mate }\end{array}$} \\
\hline & & 1 & 2 & 3 & 4 & 5 & 6 & & \\
\hline 1996 & 1995 & 10 & 3 & 1 & 2 & 0 & & $16(\mathrm{C}, \mathrm{L})$ & 0.94 \\
\hline 1997 & 1996 & 8 & 3 & 3 & 0 & 0 & 0 & $14(\mathrm{C}, \mathrm{L})$ & 0.93 \\
\hline 1998 & 1997 & 9 & 3 & 2 & 0 & 0 & 2 & $16(\mathrm{C})$ & 0.89 \\
\hline 1999 & 1998 & 10 & 3 & 1 & 1 & & & $15(\mathrm{C}, \mathrm{L})$ & 0.99 \\
\hline
\end{tabular}

consistent with the high catchability coefficients (q) we estimated from the Leslie analyses. The median of the catchability coefficients for Sharkland was 0.56 , indicating that, on average $56 \%$ of the remaining population is caught in a night of fishing. For North Sound, the catchability coefficient should be higher because $q$ is inversely proportional to the area occupied by the stock. Consistent with this, the median of the estimates of $q$ for North Sound was 0.94. The coefficients of determination $\left(R^{2}\right)$ associated with the Leslie analyses were 0.80 or greater in 14 of 18 cases and were 0.58 or greater in all but two cases: 0.03 for the 1996 and 0.29 for the 1997 Sharkland population estimates (Tables 2, 3, 5, 6). In 6 of 18 cases the Leslie estimate was higher than the observed catch, in 5 cases the Leslie estimate equaled the observed catch, and in 7 cases the Leslie estimate was replaced by the observed catch because the catch was the greater quantity (Tables 2, 3, 5, 6).

We estimated the fraction, $u$, of the population killed each year by our field operations. For North Sound, the estimated $u$ for sharks $53 \mathrm{~cm}$ PCL or less ranged from $0 \%$ to $4.5 \%$ (Table 2). For Sharkland, the estimated $u$ for sharks $62 \mathrm{~cm}$ PCL or less ranged from $0 \%$ to $4.3 \%$, except for 1998 , when the fraction of the population killed was estimated to be $11.1 \%$ (Table 5).

The four estimates of emigration from the North Sound to Sharkland were identical in 1998 (2 emigrants) and 1999 (3 emigrants; Table 4). The four estimates in 1997 differed by only a single shark. In 1996 the observed emigration estimates agreed with each other ( 7 sharks), as did the computed estimates (36 sharks).

For the years 1996, 1997, and 1998 the estimated number of survivors from the newly tagged cohorts were increased by 4,1 , and 1 , respectively, to account for sharks that were not recaptured the year after tagging but were subsequently caught. For the 1997 augmented cohort, the number of survivors was increased by 1 for the same reason.
The 14 estimates of annual survival rate ranged from 0.38 to 0.90 (mean $=0.57$ and median $=$ 0.58; Table 7). Variability across the four methods was low, except for the 1995 estimates. Survival estimates changed from year to year with a relatively high survival of 0.54 or better in 1996 and 1998 and $0.38-0.41$ in 1997 . The results for 1995 were divergent $(0.47$ and 0.90$)$.

\section{Discussion}

\section{Estimation Procedure}

This is the first study to develop and implement methods for directly measuring survival of juvenile sharks. Our strategy was to establish a known cohort by marking sharks and then estimate the number of survivors 1 year later by conducting a depletion study on the marked population. To our knowledge, only one study has used a mark-depletion model and that was for a completely closed population of mice (Skalski and Robson 1982).

A significant aspect of our study is that we were able to account for emigration from the primary study site (North Sound). The two methods for estimating emigration (observed and computed) were in close agreement except in 1996, when the observed emigration was 7 and the computed was 36 (Table 4). The value of 36 was not credible for two reasons. First, the Leslie model on which it was based clearly did not fit the data. This is because the nightly catches did not show the expected strong linear decline, and the $R^{2}$ value was only 0.03. Second, the 1996 Leslie analysis indicated a population size at least three times higher than the estimate for any other year. However, only 61 sharks were caught in 1996, less than any other year (range 80-93). In addition, the Leslie model did not fit the 1997 data well $\left(R^{2}=0.29\right)$, but the resulting estimate of computed emigration was the same as the observed emigration.

The fraction of the population captured during the sampling was high (median $q=0.56$ for Shark- 
TABLE 4.-Capture and recapture data for lemon sharks in Sharkland. Blanks indicate no sampling occurred.

\begin{tabular}{|c|c|c|c|c|c|c|c|c|c|c|c|}
\hline \multirow[b]{3}{*}{ Year } & \multirow{2}{*}{\multicolumn{6}{|c|}{ Number caught $\leq 62 \mathrm{~cm}$ on night }} & & \multicolumn{4}{|c|}{ Emigration } \\
\hline & & & & & & & & \multicolumn{2}{|c|}{ Observed } & \multicolumn{2}{|c|}{ Computed } \\
\hline & 1 & 2 & 3 & 4 & 5 & 6 & Killed $^{\mathrm{a}}$ & $\begin{array}{l}\text { Newly } \\
\text { tagged }^{b}\end{array}$ & $\begin{array}{l}\text { Aug- } \\
\text { mented } \\
\text { cohort }^{\mathrm{c}}\end{array}$ & $\begin{array}{l}\text { Newly } \\
\text { tagged }^{b}\end{array}$ & $\begin{array}{l}\text { Aug- } \\
\text { mented } \\
\text { cohort }^{\mathrm{c}}\end{array}$ \\
\hline 1995 & 42 & 19 & 14 & 9 & & & 4 & & & & \\
\hline 1996 & 17 & 11 & 23 & 10 & & & 4 & 7 & 7 & 36 & 36 \\
\hline 1997 & 44 & 5 & 4 & 2 & 25 & & 0 & 2 & 3 & 2 & 3 \\
\hline 1998 & 51 & 15 & 8 & 10 & 6 & 0 & 10 & 2 & 2 & 2 & 2 \\
\hline 1999 & 44 & 15 & 18 & 11 & 5 & & 1 & 3 & 3 & 3 & 3 \\
\hline
\end{tabular}

a The number of sharks that died during the field operation.

b Recaptures from animals tagged the previous year in North Sound when they were $53 \mathrm{~cm}$ PCL or less.

c Augmented cohort means recaptures from animals caught the previous year in North Sound—with or without tags-that were $53 \mathrm{~cm}$ or less (precaudal length) and that were released into North Sound with tags.

land). However, juvenile lemon sharks sometimes move in groups, and this introduces variability in the fraction caught. We conclude that the observed emigration is a good estimator for small sharks in Sharkland, whereas the computed emigration generally provides similar but more variable results. We also conclude that the estimated survival in 1995 based on the observed emigration (0.47) is reasonable but that the estimate based on the computed emigration (0.90) is not credible for the reasons given above.

Estimating emigration is important because, to the extent that we failed to fully account for emigration, our estimates of survival would be biased downward. The two methods we used yielded emigration rates varying year to year from $3.2 \%$ to $11.9 \%$ (compare number of emigrants from Table 4 to the number tagged the previous year in North Sound in Table 2). We believe significant emigration beyond Sharkland is unlikely for three reasons. First, telemetry studies of juvenile lemon sharks at Bimini by Morrissey and Gruber (1993a; b) demonstrated high site fidelity with limited ac-

TABLE 5.-Estimated population size in Sharkland (total of tagged and untagged sharks $\leq 62 \mathrm{~cm}$ precaudal length), handling mortality $(H)$, and fraction killed $(u)$ during field operations.

\begin{tabular}{lcccc}
\hline Year & $H(\%)$ & $\begin{array}{c}\text { Estimated } \\
\text { population } \\
(\text { method) }\end{array}$ & $\begin{array}{l}R^{2} \text { for } \\
\text { Leslie } \\
\text { estimate }\end{array}$ & $\begin{array}{c}u \\
(\%)\end{array}$ \\
\hline 1995 & 4.8 & $92(\mathrm{~L})$ & 0.96 & 4.3 \\
1996 & 6.6 & $315(\mathrm{~L})$ & 0.03 & 1.3 \\
1997 & 0 & $80(\mathrm{C})$ & 0.29 & 0 \\
1998 & 11.1 & $90(\mathrm{C})$ & 0.92 & 11.1 \\
1999 & 1.1 & $99(\mathrm{~L})$ & 0.87 & 1.0 \\
\hline
\end{tabular}

${ }^{a}$ Derived from the capture data in Table 4 as the maximum of the Leslie population estimate (L) and the number of sharks caught (C). tivity spaces. Second, Clermont and Gruber (in press) showed that experimentally displaced lemon sharks return to their home ranges, confirming high site fidelity. Third, no North Sound emigrants ( $\leq 62 \mathrm{~cm}$ PCL) were captured outside the study area during extensive sampling activities associated with other projects.

Handling mortality is important because survival may depend on the population size. If the population were artificially reduced, the survival rate might not pertain to the natural situation. Fortunately, the estimated fraction of the population killed during spring field operations was always less than 5\%, except in 1998 when it was $11 \%$ in Sharkland (Tables 2, 5). The mortality in 1998 occurred when temperature was $38^{\circ} \mathrm{C}$ and water depth in the holding pen was extremely low due to spring tides.

The estimates of survival rate appear to be reliable for several reasons. The estimated capture efficiency of the gill net was so high that a large fraction of the sharks present were captured. For example, our median estimate of $q$ for Sharkland, 0.56 , implies that after 4 nights of fishing we can expect to have caught $96 \%$ of the population. This is reflected in the rapid decline of catch rate over time, the generally high coefficients of determination of the Leslie regressions, and the fact that estimated population size was generally close to or equaled the actual catch. Additionally, we used four variations on the basic methodology and, with the one exception discussed above, the results within a year were remarkably consistent. We conclude that the estimates are sufficiently precise to enable us to track yearly changes in survival rate.

We believe the estimates of survival with emigration based on the observed counts are the most reliable. Using the newly tagged cohorts enabled 
TABLE 6.- Recaptures in North Sound of lemon sharks from the previous year's augmented cohort and estimates of the number of survivors. Blank cells indicate no sampling occurred; $\mathrm{L}=$ Leslie estimate; $\mathrm{C}=$ total number of lemon sharks caught.

\begin{tabular}{crrrrrrrc}
\hline \multirow{2}{*}{$\begin{array}{c}\text { Sampling } \\
\text { year }\end{array}$} & \multicolumn{4}{c}{ Number recaptured on night } & & $\begin{array}{c}\text { Estimated } \\
\text { survivors } \\
\text { (method) }\end{array}$ & $\begin{array}{c}R^{2} \text { for } \\
\text { Leslie } \\
\text { estimate }\end{array}$ \\
\hline 1996 & 10 & 3 & 1 & 2 & 0 & & $16(\mathrm{C}, \mathrm{L})$ & 0.94 \\
1997 & 9 & 4 & 6 & 1 & 0 & 0 & $21(\mathrm{~L})$ & 0.80 \\
1998 & 16 & 3 & 2 & 0 & 0 & 2 & $23(\mathrm{C})$ & 0.95 \\
1999 & 15 & 4 & 1 & 1 & & & $21(\mathrm{C}, \mathrm{L})$ & 0.99 \\
\hline
\end{tabular}

us to estimate survival for 1995 . Consequently, the following discussion pertains only to the survival estimates based on the newly tagged cohort and observed emigration (see column 2 in Table 7).

\section{Biological Significance of Findings}

This study estimated the survival of sharks 53 $\mathrm{cm}$ PCL or less. In the first year of this study, the sharks tagged were a mixture of ages 0,1 , and 2 . In the subsequent years, the newly tagged sharks must have been age 0 for the most part because almost all the age- 1 and age- 2 sharks that were 53 $\mathrm{cm}$ or less would have been tagged the previous year. We note that all our estimates of survival for augmented cohorts pertain to a mixture of ages. However, there was little difference in the estimates for the newly tagged and augmented cohorts. Thus, we have little evidence that age was an important factor influencing survival of sharks $53 \mathrm{~cm}$ or less.

Using a Leslie matrix model, Hoenig and Gruber (1990) found that an annual survival rate of 0.39 would, on average, produce a stable lemon shark population. This value is somewhat lower than the survival rates obtained in this study (median of column 2 in Table $7=0.54$ ) but close to the values observed for 1995 (0.47) and 1997 (0.38). An exact agreement between results of the 1990 Leslie matrix model and field results from the present

TABLE 7.-Estimates of annual survival rate for lemon sharks ( $\leq 53 \mathrm{~cm}$ precaudal length) in North Sound. Newly tagged and augmented refer to the definition of the tagged cohort; observed count and computed refer to the method of estimating emigration from North Sound.

\begin{tabular}{|c|c|c|c|c|}
\hline \multirow[b]{3}{*}{ Year } & \multicolumn{4}{|c|}{ Method } \\
\hline & \multicolumn{2}{|c|}{ Newly tagged cohort } & \multicolumn{2}{|c|}{ Augmented cohort } \\
\hline & Observed & Computed & Observed & Computed \\
\hline 1995 & 0.47 & 0.90 & & \\
\hline 1996 & 0.65 & 0.65 & 0.69 & 0.69 \\
\hline 1997 & 0.38 & 0.38 & 0.41 & 0.41 \\
\hline 1998 & 0.60 & 0.60 & 0.57 & 0.54 \\
\hline
\end{tabular}

study should not be expected because Hoenig and Gruber (1990) reported that their Leslie model estimate was sensitive to minor changes in input parameter values. Results of this study support the assumption that first-year survival can be adequately determined by the Leslie matrix model (or similar life table methods), and this is important because these models are being used for management of shark stocks (Cortes 1998). Thus, the direct estimates of mortality in this investigation provide the first clear support for the use of demographic analyses for shark management.

This study breaks new ground by providing insights into the magnitude and nature of year-toyear variability in survival. In 2 of the 4 years, the estimated survival rate was roughly $40 \%$, whereas in the other 2 years it was $60 \%$ or greater (Table 7). The survival appeared to be negatively correlated with abundance of the sharks (Figure 2). If additional data confirm this pattern, we will have a descriptive and predictive tool relating survival to population abundance (density). Hoenig and Gruber's (1990) findings provided a rough limit to how much a population could respond to a change in abundance of neonates: the $39 \%$ juvenile survival rate they estimated logically cannot increase to more than $100 \%$. This established an upper limit to the amount of adult exploitation that is sustainable. The current study goes beyond this by allowing us to predict how much juvenile survival changes in response to population change over a range of observed neonate abundances (Figure 2).

Fishing directly affects the number of neonates produced, and now we begin to understand how this translates into the number of survivors at age 1. The production of yearling sharks is the product of initial abundance and survival. We would expect that the production curve would be a dome-shaped or asymptotic function of initial abundance in accordance with stock recruitment theory. Furthermore, the slope of the curve at the origin cannot 


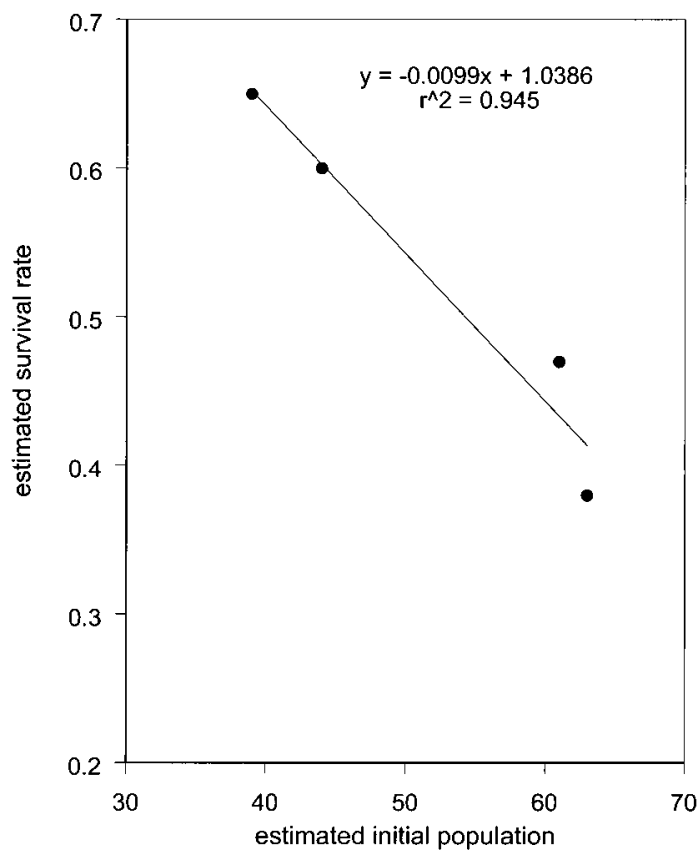

Figure 2.-Estimated annual survival rate of lemon sharks ( $\leq 53 \mathrm{~cm}$ PCL) as a function of the estimated abundance at the time of tagging. Estimates are for a newly tagged cohort with observed emigration.

exceed 1.0 because there cannot be more survivors than the number of pups born. The recruitment curve for Bimini lemon sharks appears quite flat topped over the range of initial population sizes observed (Figure 3 ) and suggests that the maximum number of pups that can survive per year is around 30 .

\section{Future Research}

Having demonstrated the feasibility of estimating annual survival of a population of juvenile sharks, we believe future research can build on these findings in several ways. First, the lemon shark study at Bimini should be continued to determine how much survival varies from year to year, to determine whether survival really is density-dependent, as indicated in Figure 2, and to describe more fully the curve relating number of survivors to the initial number of sharks present. The study should be extended to estimate the survival of yearlings and, if possible, of age- 2 sharks. Emigration appears to be higher for larger lemon sharks, so particular attention will be required to quantify this. It would also be interesting to attempt to estimate the survival of sharks in Sharkland to begin to see the variability in survival over

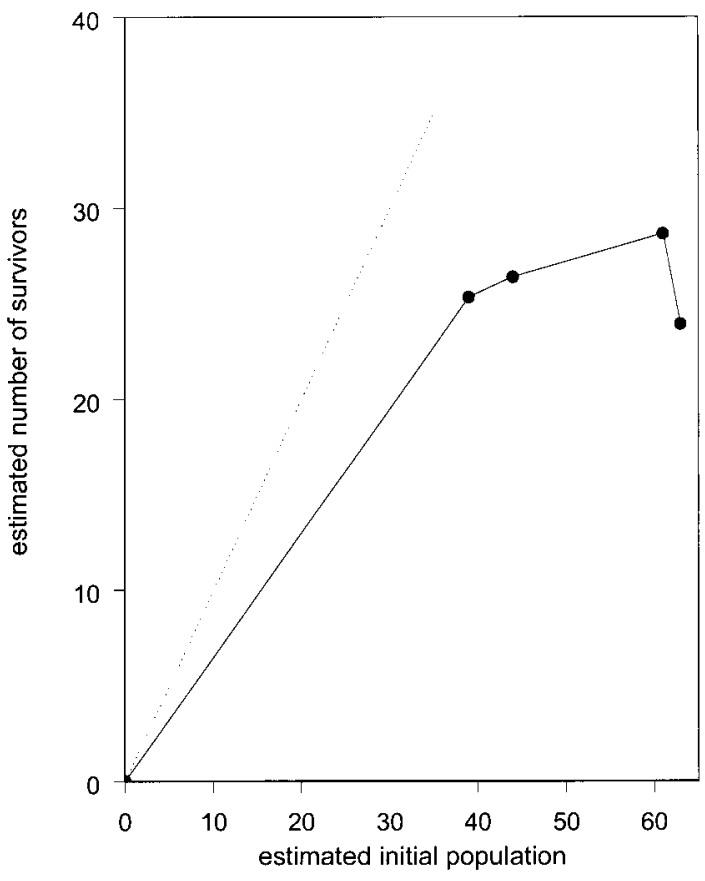

FIGURE 3.-Estimated number of lemon sharks $(\leq 53$ $\mathrm{cm}$ PCL) surviving a year as a function of the estimated abundance at the time of tagging. The recruitment curve must be to the right of the $45^{\circ}$ dashed line.

space. Again, quantifying emigration is a critical factor.

From an ecological perspective, it is important to understand how factors such as growth and the availability of food and space may affect the survival of juvenile sharks. A contemporary issue is establishing how much nursery area is required to support a juvenile lemon shark. The available habitat can be quantified, and this can be divided by the carrying capacity (currently estimated to be 30 sharks $\leq 53 \mathrm{~cm}$ in North Sound) to establish the amount of habitat required per shark. This can be compared to alternative calculations based on the measured activity space of sharks and the degree to which sharks share habitat. Measures of critical habitat must consider the quality of the habitat. From estimates of survival and growth of juvenile lemon sharks, it is possible to calculate energetic needs of the population of sharks $53 \mathrm{~cm}$ PCL or less. These energy needs can then be related to production of prey in North Sound.

This study should be repeated for lemon sharks in other areas and for other species of elasmobranchs. The difficulty in doing this is finding a nursery area of manageable size where the population is relatively closed to emigration. 


\section{Acknowledgments}

We dedicate this paper to the many volunteers who gave up countless hours of sleep dodging lightning, mosquitoes, and biting sharks to collect the data presented here. We gratefully acknowledge the seminal ideas provided by Charles Manire at the inception of this work. We thank Melissa Drake, Kevin Feldheim, and Tim Calver for running the field operation. We are grateful to Colin Higgs and Michael Braynan, directors of the Bahamas Department of Fisheries, for issuing a scientific permit in support of our research. We also thank the people of Bimini, especially Percy Duncombe and the Bimini bonefishermen, who put up with the "crazy scientists" on the flats. The study would not have been possible without financial support from the Bimini Biological Field Station, Earthwatch Institute, National Science Foundation (NSF-OCE 97-12793), and Department of Education, State of Florida (FLORIDA 8749703000001). We are also indebted to Tadashi and Toshi Fujino for generous personal support. We gratefully acknowledge the following corporate support: Mario Aiello, owner of Davey Marine; the late Dan Schaad of Mercury Division, Brunswick Corporation; Destron-Fearing Corporation, especially Sean Casey; Mike O'Brian, President, Bimini Island Air; and Pelican Products.

\section{References}

Braaten, D. O. 1969. Robustness of the deLury population estimator. Journal of the Fisheries Research Board of Canada 26:339-355.

Brown, C. A., and S. H. Gruber. 1988. Age assessment of the lemon shark, Negaprion brevirostris, using tetracycline validated vertebral centra. Copeia 1988:747-753.

Clermont, S., and S. H. Gruber. (In press.). Lemon sharks possess a homing mechanism. Marine $\mathrm{Bi}$ ology.

Cortes, E. 1998. Demographic analysis as an aid in shark stock assessment and management. Fisheries Research 39:199-208.

Gruber, S. H., and R. G. Stout. 1983. Biological materials for the study of age and growth in a tropical elasmobranch, Negaprion brevirostris (Poey). NOAA Technical Report NMFS 8:193-205.

Hoenig, J. M., and S. H. Gruber. 1990. Life-history patterns in the elasmobranchs: implications for fisheries management. Pages 1-16 in H. L. Pratt, S. H. Gruber,, and T. Taniuchi, editors. Elasmobranchs as living resources: advances in the biology, ecology, systematics, and the status of the fisheries. National Oceanic and Atmospheric Administration Technical Report NMFS 90, U.S. Department of Commerce.

Hoff, T. B. 1990. Conservation and management of the western North Atlantic shark resource based on the life history strategy limitations of the sandbar shark. Doctoral dissertation. University of Delaware, Newark.

Leslie, P. H., and D. H. S. Davis. 1939. An attempt to determine the absolute number of rats on a given area. Journal of Animal Ecology 8:94-113.

Manire, C. A., and S. H. Gruber. 1993. A preliminary estimate of natural mortality of Age-0 lemon sharks, Negaprion brevirostris. NOAA Technical Report NMFS 115:65-71.

Morrissey, J. F., and S. H. Gruber. 1993a. Home range of juvenile lemon sharks, Negaprion brevirostris (Poey). Copeia 1993:425-434.

Morrissey, J. F., and S. H. Gruber. 1993b. Habitat selection by juvenile lemon sharks, Negaprion brevirostris. Environmental Biology of Fishes 38:311319.

Skalski, J., and D. S. Robson. 1982. A mark and removal field procedure for estimating population abundance. Journal of Wildlife Management 46:741751.

Sminkey, T. R., and J. A. Musick. 1996. Demographic analysis of the sandbar shark, Carcharhinus plumbeus, in the western North Atlantic. Fishery Bulletin, US, 94:341-347. 